\title{
The evaluation of relationship between blood pressure and dialysate Na concentration in chronic hemodialysis patients
}

\author{
Narges Sadat Zahed, Omid Gharooi*, Latif Gachkar, Hajar Nikbakht \\ Department of Nephrology, Loghman Hakim Clinical Research Development Center, Shahid Beheshti University of Medical sciences (SBUM), Tehran, \\ Iran
}

\section{A R T I C LE IN F O}

Article Type:

Original

\section{Article History:}

Received: 14 February 2016

Accepted: 1 May 2016

Published online: 9 May 2016

Keywords:

Blood pressure

Dialysis

Dialysate sodium concentration

Hemodialysis

Intradialysis weight gain

\begin{abstract}
A B S T R A C T
Introduction: Hypertension is one of the traditional risk factors of cardiovascular disease (CVD). Extra cellular volume expansion and $\mathrm{Na}$ retention remain the main cause of hypertension.

Objectives: The aim of this study was to investigate the relation between concentration of $\mathrm{Na}$ dialysate and blood pressure (BP) in chronic hemodialysis (HD) patient.

Patients and Methods: This cross-sectional study was performed on 266 adult patients undergoing HD for at least three months. Pre-HD systolic BP (SBP) and post-HD SBP during 4 weeks were measured in relation to $\mathrm{Na}$ dialysate concentration. The other main factors affecting the post-dialysis BP, such as body mass index (BMI), pump speed, dialysis solution temperature, duration of dialysis and intradialysis weight gain (IDWG) were also considered. Mean of $\triangle$ SBP (post-HD SBP - pre-HD SBP) in each patient in 12 session of HD was measured and statistically analyzed in relation to dialysate Na with SPSS 21. Backward multivariable linear regression analysis and Pearson's correlation coefficients were used to evaluate the correlation between sodium gradient and $\triangle$ SBP.

Results: SBP was significantly changed before and after dialysis in relation to dialysate $\mathrm{Na}$ $(P<0.001)$. The Pearson's correlation between $\triangle$ SBP with dialysate sodium and blood flow rate (pump speed) were statistically significant $(P<0.05)$.

Conclusion: We found that changes in SBP before and after dialysis is significantly associated with dialysate sodium concentration.
\end{abstract}

Implication for health policy/practice/research/medical education:

About $50 \%$ to $90 \%$ of dialysis population have hypertension. A relation between chronic volume expansion and mortality is well established. Dialysate sodium concentration is proposed as one of several factors which can control the blood pressure (BP) in dialysis patients. The aim of this study was to investigate the relation between concentration of Na dialysate and BP in chronic hemodialysis (HD) patients. This cross-sectional study was performed on 266 adult patients undergoing HD for at least three months. We found that changes in systolic BP before and after dialysis is significantly associated with dialysate sodium concentration.

Please cite this paper as: Zahed NS, Gharooi O, Gachkar L, Nikbakht H.The evaluation of relationship between blood pressure and dialysate Na concentration in chronic hemodialysis patients. J Renal Inj Prev. 2016;5(3):118-122. DOI: 10.15171/jrip.2016.25

\section{Introduction}

Cardiovascular complications and more specifically hypertension are the most common causes of death in chronic dialysis patients (1). About $50 \%$ to $90 \%$ of dialysis population have hypertension (2). According to a cohort study that was performed by Agarwal et al on 2535 patients, $86 \%$ of them had hypertension although after antihypertensive medication in $76 \%$ of patients only $30 \%$ of cases had an appropriate responds to treatment (3).
Extracellular volume expansion and $\mathrm{Na}$ retention remain the main causes of hypertension in end-stage kidney failure (ESKF). A relation between chronic volume expansion and mortality is well established dialysate sodium concentration is proposed as one of several factors which can control the blood pressure (BP) in dialysis patients (4-6).

The first dialysate sodium concentration was $126.5 \mathrm{meq} / \mathrm{L}$ (Kolff 1974). In order to prevent further complications 
such as sudden decrease in serum osmolality, muscle cramps and hypotension during dialysis, the dialysate sodium concentration increase gradually to $135-145 \mathrm{meq} / \mathrm{L}$. Although increasing dialysate sodium concentration, can lead to thirst, increased BP and weight gain during the dialysis. Davenport et al conducted a study on 469 dialysis patients, which concluded that lower sodium dialysate can gain BP control (4). Though the mentioned work is in contrast with investigation among 2187 patients in 2008, which did not show the relationship between BP and dialysate sodium concentration (5). Krautzig et al could reduce the mean arterial pressure from 108 to 98 by decreasing the dialysate sodium concentration from 140 to 135 in a period of 15 to 20 weeks (6). In contrast, Kooman et al were unable to decrease BP by reducing dialysate sodium from 140 to 136 (7). Sayarlioglu et al selected 135 $\mathrm{meq} / \mathrm{L}$ dialysate $\mathrm{Na}$ concentration for patients with serum sodium lower than $137 \mathrm{meq} / \mathrm{L}$ and $137 \mathrm{meq} / \mathrm{L}$ dialysate sodium concentration for patients with serum sodium higher than $137 \mathrm{meq} / \mathrm{L}$. In the same study a significant reduction in pre-dialysis systolic BP (SBP) (151.7 \pm 17.7 versus $179 \pm 24.8)$ and post-dialysis SBP $(132.3 \pm 16.4$ versus $141.4 \pm 28.8)$ were observed after 8 weeks (8). Finally, the large scale study on 23962 dialysis patients carried out in 2014 shows no significant difference in pre-dialysate SBP between patients with typical dialysate sodium concentration of $135 \mathrm{meq} / \mathrm{L}$ to $145 \mathrm{meq} / \mathrm{L}$ and patients with individualized dialysate sodium concentration of $125 \mathrm{meq} / \mathrm{L}$ to $155 \mathrm{meq} / \mathrm{L}$ (9). The different results obtained by different groups convinced the authors to conduct the current work among 266 patients to reexamine the effect of dialysate sodium concentration on SBP in hemodialysis (HD) patients.

\section{Objectives}

The aim of this study was to investigate the relation between concentration of $\mathrm{Na}$ dialysate and $\mathrm{BP}$ in chronic HD patients.

\section{Patients and Methods}

In this observational study, patients were enrolled from three different dialysis centers from educational hospital in Tehran including Loughman Hakim hospital, Ashrafi Isfehani hospital and the West center.

All selected patients were undergoing HD three times per week (4 hours each session) for more than two months until they reach to their dry weight. Then, 266 dialysis patients were enrolled in the study.

The project is performed by nephrologists and dialysis staff. This investigation is not considered as human subject research, because of patients undergoing ordinary treatment. The dialysis is performed for all participants with volumetric dialysis machines (JMS, SD 50).

The standard dialysis prescription included session length of dialysis (about 4 hours) with individual blood flow rate based on patients' condition (from $210 \mathrm{cc} / \mathrm{min}$ to $350 \mathrm{cc}$ / $\mathrm{min}$ ) and dialysate flow rate of $500 \mathrm{~mL} / \mathrm{min}$. The dialysis solution contains the following concentration: potassium,
1-3 meq/L; bicarbonate, 35-40 meq/L; magnesium, 1.0 $\mathrm{meq} / \mathrm{L}$; and calcium, $2.5 \mathrm{meq} / \mathrm{L}$. Glucose concentration was $200 \mathrm{mg} / \mathrm{dl}$.

BP is monitored before and after the dialysis with calibrated mercury sphygmomanometer in each session by dialysis nurse during 4 weeks.

All data including patient age, duration of ESKD, etiology of ESKD, pre- and post-dialysis weight, amount of ultrafiltration (UF), pre- and post-dialysis BP, blood flow rate (pump speed), dialysis temperature, body mass index (BMI) and medication such as antihypertensive drugs were collected in data sheets. Dietary $\mathrm{Na}$ intake was not measured. In patients with high BP (define as BP > 140/90 $\mathrm{mm} \mathrm{Hg}$ ) sodium dialysate decreased to $133 \mathrm{meq} / \mathrm{L}$, and patients with low BP (define as BP $<100 / 80 \mathrm{~mm} \mathrm{Hg}$ ), $\mathrm{Na}$ dialysate increased to $147 \mathrm{meq} / \mathrm{L}$.

Moreover, the patient's medications such as anti-hypertensive drugs are not modified.

We predict the post-dialysis BP with the following formula: SBP after dialysis - SBP before dialysis $=-41.5+0.11$ (sodium of dialysate) -0.3 (speed of pump).

\section{Ethical issues}

The research followed the tenets of the Declaration of Helsinki; informed consent was obtained; and the research was approved by the ethical committee of Shahid Beheshti University of Medical Sciences.

\section{Statistical analysis}

Data variables are summarized as mean \pm standard deviation (SD) or median with interquartile range. Stepwise multivariable linear regression and Pearson's correlation coefficient was used to evaluate the correlation between post- and pre-dialysis BP with independent variables such as dialysate sodium concentration, intradialysis weight gain (IDWG ), duration of dialysis and dialysis fluid temperature. Post-dialysis BP predicted by backward multivariable linear regression analysis (Figures 1 and 2). A $P$ value $<0.05$ was recognized statistically significant.

\section{Results}

A total of $266 \mathrm{HD}$ patients were studied (153 were men). Mean age was $57.97 \pm 13.33$ years and $71(26.6 \%)$ had diabetes, 98 (36.8\%) had hypertension. Mean pre- and postHD-BP were $127.14 \pm 17.55 \mathrm{~mm} \mathrm{Hg}$, and $116.23 \pm 14.85$ $\mathrm{mm} \mathrm{Hg}$, respectively. Mean Na dialysate was $138.16 \pm 2.06$ meq/L, IDWG $2.18 \pm 0.91 \mathrm{~kg}$, dialysis fluid temperature $36.28 \pm 0.29^{\circ} \mathrm{C}$, pump speed $276.17 \pm 21.47 \mathrm{cc} / \mathrm{min}$, duration of sessions $3.91 \pm 0.22$ hours (Tables 1 and 2). In the second step, delta of SBP $(\triangle \mathrm{SBP})$, post-HD SBP - pre-HD SBP was calculated. Analysis performed in six steps. In stepwise multiple regression model, $\triangle \mathrm{SBP}$ was the dependent variable, and the other variable were independent. At second step dialysis temperature, in the third step BMI, months' of dialysis in fourth step, duration of dialysis in fifth and in sixth step and IDWG were excluded (Table 3). With this model variables with low significancy were excluded (IDWG, dialysate temperature, BMI, duration of 


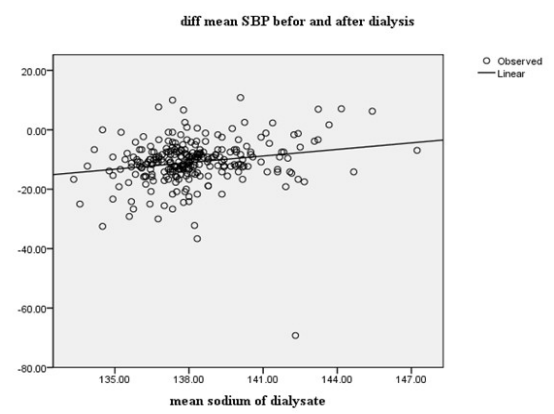

Figure 1. Systolic blood pressure (SBP) and mean sodium concentration of dialysate.

Table 1. Etiology of ESKF in dialysis patients ${ }^{a}$

\begin{tabular}{lc}
\hline Etiology ESKD & Prevalence \\
\hline Diabetes & $71(26.6)$ \\
BP & $98(36.8)$ \\
Polycystic kidney & $12(4.5)$ \\
Kidney stone & $10(3.8)$ \\
Undermined & $10(3.8)$ \\
Missed data & $65(24.4)$ \\
\hline
\end{tabular}

Abbreviations: BP: Blood pressure; ESKF, end-stage kindney failure.

${ }^{a} \mathrm{~N}=266$. Values are expressed as number (percentage).

Table 2. Mean \pm SD of variables

\begin{tabular}{lccc}
\hline Variable & Min & Max & Value \\
\hline Age (years) & 25 & 83 & $57.97 \pm 13.33$ \\
BMI( kg/m ${ }^{2}$ ) & 15 & 43 & $24.96 \pm 3.65$ \\
Dialysis duration (month) & 2 & 312 & $49.01 \pm 46.91$ \\
Pre dialysis systolic pressure (mm & 69.2 & 203.8 & $127.14 \pm 17.55$ \\
$\mathrm{Hg})$ & 65.4 & 167.5 & $116.23 \pm 14.85$ \\
Post dialysis systolic (mm Hg) & 210 & 325.56 & $276.17 \pm 21.47$ \\
Dialysis pumps speed (m/min) & 35 & 36.91 & $36.28 \pm 0.29$ \\
Dialysis solution temperature (C) & 2.43 & 4 & $3.91 \pm 0.22$ \\
Dialysis session duration (h) & 0.06 & 4.65 & $2.18 \pm 0.91$ \\
Interadialytic weight gain (kg) & 133.33 & 147.27 & $138.16 \pm 2.06$ \\
\hline $\begin{array}{l}\text { Dialysate sodium concentration } \\
\text { (mEq/L) }\end{array}$ & & & \\
\hline
\end{tabular}

dialysis). In the final step only dialysate $\mathrm{Na}$ concentration and pump speed remained $(P<0.01)$. A significant positive correlation between delta SBP and dialysate $\mathrm{Na}$ was found. These findings imply that, BP level was significantly different before and after dialysis in relation to dialysate $\mathrm{Na}(P<0.001$; Figures 1 and 2).

Additionally the correlation between $\triangle \mathrm{SBP}$ and dialysate sodium and pump speed was statistically significant $(P<0.05)$.

\section{Discussion}

BP depends on heart output and peripheral vascular resistance. Increased dietary sodium intake results in higher plasma sodium concentrations. If sodium intake exceeds the capacity of renal excretion plasma volume and BP will increase (10).

Moreover, it is demonstrated that the limitation in daily salt intake to the amount of 4.4 to 7.4 gram/day can reduce

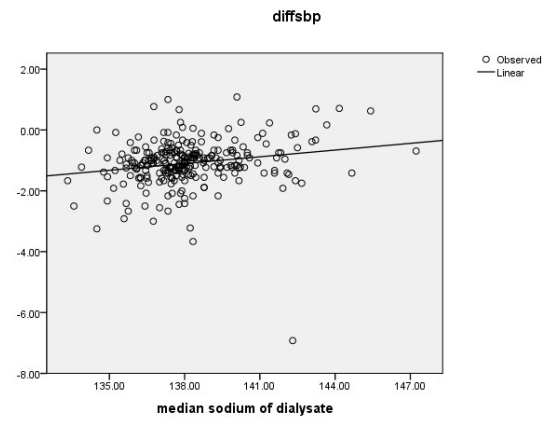

Figure 2. Systolic blood pressure (SBP) and median sodium concentration of dialysate

SBP by 3.7 to $4.9 \mathrm{~mm} \mathrm{Hg}$ and diastolic BP by 0.9 to $2.9 \mathrm{~mm}$ $\mathrm{Hg}$ (10).

It should be noted that all factors which reduce plasma sodium concentration, could contribute to reduction of BP in hemodialysis patients too.

Extracellular volume expansion and $\mathrm{Na}$ retention remain the main causes of hypertension in HD patients. There is an association between extracellular fluid volume (ECFV) expansion and diastolic dysfunction in dialysis patients. Recent attention has been called to none osmotic accumulation of $\mathrm{Na}$ in subcutaneous space and other organs, elevated $\mathrm{Na}$ stores may impact inflammatory and cardiac fibrotic process via vascular endothelial growth factor. Also $\mathrm{Na}$ accumulation in arterial smooth muscle may contribute to increased vascular stiffness (11).

In $\mathrm{HD}$ patients most of $\mathrm{Na}$ intake is driven by salt ingestion, another source of $\mathrm{Na}$ is diffusive gain from dialysis solution when dialysate sodium is greater than the predialysis plasma level. The difference between plasma and dialysate sodium concentration induces sodium gradient across dialysis membrane. Sodium concentration in the dialysate solution should be 6 to $7 \mathrm{meq} / \mathrm{L}$ higher than the plasma sodium concentration to obtain isonatremic dialysis. In fact, Gibss-Donnan effect compensates this gradient in vivo. Gibss-Donnan effect is due to a large portion of the negative charge in the plasma protein which is not able to pass through dialysis membrane. This effect induces $4 \%$ to $5 \%$ reduction in sodium diffusion, itself (12). In a study on 2187 patients, conducted by Davenport et al, for one week, very little change in the BP was observed and, therefore, it failed to prove the relationship between sodium dialysate concentration and BP (5). Whereas in investigations by Elshahawy et al and Movilli et al, during a period of at least six months, statistically and clinically significant relationship was achieved $(13,14)$. Assessing $\mathrm{Na}$ kinetics during a dialysis session by sequential plasma and dialysate $\mathrm{Na}$ measurement is impractical in clinical practice, therefore, we decided to asses post-dialysis BP just in relation to $\mathrm{Na}$ dialysate (dietary $\mathrm{Na}$ intake and plasma Na were not measured).

We found that if dialysate $\mathrm{Na}$ is decreased about 13.3 $\mathrm{meq} / \mathrm{L}$ (from $147.33 \pm 2.06$ to $133.33 \pm 2.06$ ) BP will decrease about $10.91 \mathrm{~mm} \mathrm{Hg}$. This positive correlation is very important because we know with this strategy not 
only we can control BP in hypertensive patients, but also we can predict post-dialysis BP according to Na dialysate and pump speed.

We also found out that IDWG has positive correlation with Na dialysate (Table 4). IDWG is not only important in control of BP in hypertensive patients but also it is important in decreasing of BP in hypotensive patients (15). Another important factor is pump speed, if pump speed decreases from $210 \mathrm{cc} / \mathrm{min}$ to 325.56, the BP will decrease significantly $(P<0.001)$.

We explained that differences in our results with other studies may be due to the duration of follow up. In the study of Davenport et al, was done only for one week, duration of study was too short, whereas changes in $\mathrm{Na}$ concentration should be made gradually over the time in order to changes in ECFV, and storing of $\mathrm{Na}$ in body.
Conclusion

We found post-dialysis BP is significantly correlated with changes in dialysate sodium concentration. This Relationship is independent of other clinical factors.

\section{Limitations of the study}

The limitations of our stuy was small sample size and short duration of investigation. Moreover, our study was observational, while prospective studies in order to predict BP in relation to $\mathrm{Na}$ accumulation and its consequences is needed.

\section{Acknowledgments}

We woulde like to acknowledge Loghman-Hakim Clinical Research Development Center because of its kind supports.

Table 3. Variables partial correlation

\begin{tabular}{|c|c|c|c|c|c|c|}
\hline \multirow{2}{*}{\multicolumn{2}{|c|}{ Model }} & \multirow{3}{*}{$\begin{array}{c}\text { Standardized coefficients beta } \\
-0.007^{\mathrm{a}}\end{array}$} & \multirow{3}{*}{$\begin{array}{c}\mathbf{t} \\
-0.111\end{array}$} & \multirow{3}{*}{$\begin{array}{c}P \\
0.912\end{array}$} & \multirow{3}{*}{$\begin{array}{c}\begin{array}{c}\text { Partial } \\
\text { Correlation }\end{array} \\
-0.007\end{array}$} & \multirow{3}{*}{$\begin{array}{c}\text { Collinearity Statistics } \\
\text { Tolerance } \\
0.813\end{array}$} \\
\hline & & & & & & \\
\hline 2 & Mean temperature of dialysate & & & & & \\
\hline \multirow[t]{2}{*}{3} & Mean temperature of dialysate & $-0.008^{b}$ & -0.127 & 0.899 & -0.008 & 0.823 \\
\hline & Body mass index & $0.009^{b}$ & 0.148 & 0.882 & 0.009 & 0.890 \\
\hline \multirow[t]{3}{*}{4} & Mean temperature of dialysate & $-0.009^{c}$ & -0.138 & 0.890 & -0.009 & 0.824 \\
\hline & Body mass index & $0.005^{c}$ & 0.086 & 0.931 & 0.005 & 0.909 \\
\hline & Months of dialysis & $0.025^{c}$ & 0.412 & 0.681 & 0.026 & 0.956 \\
\hline \multirow[t]{4}{*}{5} & Mean temperature of dialysate & $-0.011^{d}$ & -0.175 & 0.862 & -0.011 & 0.831 \\
\hline & Body mass index & $0.004^{d}$ & 0.071 & 0.944 & 0.004 & 0.911 \\
\hline & Months of dialysis & $0.023^{d}$ & 0.396 & 0.693 & 0.025 & 0.958 \\
\hline & Mean time of dialysis & $-0.024^{d}$ & -0.399 & 0.691 & -0.025 & 0.951 \\
\hline \multirow[t]{5}{*}{6} & Mean temperature of dialysate & $0.010^{e}$ & 0.167 & 0.868 & 0.010 & 0.913 \\
\hline & Body mass index & $-0.015^{e}$ & -0.252 & 0.801 & -0.016 & 0.994 \\
\hline & Months of dialysis & $0.021^{e}$ & 0.359 & 0.720 & 0.022 & 0.959 \\
\hline & Mean time of dialysis & $-0.029^{e}$ & -0.487 & 0.627 & -0.030 & 0.957 \\
\hline & Mean weight gain between dialysis & $-0.070^{e}$ & -1.110 & 0.268 & -0.069 & 0.837 \\
\hline
\end{tabular}

a Predictors in the Model: (Constant), mean time of dialysis, months of dialysis, mean speed of pomp, body mass index, mean sodium of dialysate, mean weight gain between dialysis.

${ }^{b}$ Predictors in the Model: (Constant), mean time of dialysis, months of dialysis, mean speed of pomp, mean sodium of dialysate, mean weight gain between dialysis.

'Predictors in the Model: (Constant), mean time of dialysis, mean speed of pomp, mean sodium of dialysate, mean weight gain between dialysis.

dPredictors in the Model: (Constant), mean speed of pomp, mean sodium of dialysate, mean weight gain between dialysis.

e Predictors in the Model: (Constant), mean speed of pomp, mean sodium of dialysate.

${ }^{\mathrm{f}}$ Dependent Variable: diff mean SBP before and after dialysis.

Table 4. Pearson's correlation

\begin{tabular}{|c|c|c|c|c|c|}
\hline & & $\begin{array}{l}\text { Difference mean SBP } \\
\text { before and after dialysis }\end{array}$ & $\begin{array}{l}\text { Mean sodium } \\
\text { of dialysate }\end{array}$ & $\begin{array}{l}\text { Mean weight gain } \\
\text { between dialysis }\end{array}$ & $\begin{array}{l}\text { Mean speed } \\
\text { of pomp }\end{array}$ \\
\hline \multirow[t]{3}{*}{ Difference mean SBP before and after dialysis } & Pearson's correlation & 1 & $0.197 * *$ & -0.095 & $-0.321 * *$ \\
\hline & Sig. (2-tailed) & & 0.001 & 0.122 & 0.000 \\
\hline & $\mathrm{N}$ & 266 & 266 & 266 & 266 \\
\hline \multirow[t]{3}{*}{ Mean sodium of dialysate } & Pearson's correlation & $0.197 * *$ & 1 & $0.236 * *$ & $-0.291 * *$ \\
\hline & Sig. (2-tailed) & 0.001 & & 0.000 & 0.000 \\
\hline & $\mathrm{N}$ & 266 & 266 & 266 & 266 \\
\hline \multirow[t]{3}{*}{ Mean weight gain between dialysis } & Pearson's correlation & -0.095 & $0.236^{* *}$ & 1 & $0.244^{* *}$ \\
\hline & Sig. (2-tailed) & 0.122 & 0.000 & & 0.000 \\
\hline & $\mathrm{N}$ & 266 & 266 & 266 & 266 \\
\hline \multirow[t]{3}{*}{ Mean speed of pomp } & Pearson's correlation & $-0.321 * *$ & $-0.291 * *$ & $0.244 * *$ & 1 \\
\hline & Sig. (2-tailed) & 0.000 & 0.000 & 0.000 & \\
\hline & $\mathrm{N}$ & 266 & 266 & 266 & 266 \\
\hline
\end{tabular}

**Correlation is significant at the 0.01 level. 


\section{Authors' contribution}

NSZ; has designed the idea of study, wrote the discussion part, and observed accuracy and validity of study protocol. OG; collected data and fallow the studies objects. LG; performed statistical analysis. $\mathrm{HN}$ wrote the article paper and edited the manuscript.

\section{Conflicts of interest}

The authors declare no conflict of interest.

\section{Ethical considerations}

Ethical issues (including plagiarism, data fabrication, double publication) have been completely observed by authors.

\section{Funding/Support}

This article is extracted from residential thesis of Omid Gharooi. This study was supported by a grant from Shahid Beheshti University of Medical Sciences (Grant \# 55, 2010).

\section{References}

1. Foley RN, Herzog CA, Collins AJ. Blood pressure and long-term mortality in United States hemodialysis patients: USRDS Waves 3 and 4 Study. Kidney Int. 2002;62:1784-90. doi: 10.1046/j.1523-1755.2002.00636.x

2. Hörl MP, Hörl WH. Hemodialysis-associated hypertension-Pathophysiology and therapy. Am J Kidney Dis. 2002;39:227-24. doi: 10.1053/ajkd.2002.30542

3. Agarwal R, Nissenson AR, Batlle D, Coyne DW, Trout JR, Warnock DG. Prevalence, treatment, and control of hypertension in chronic hemodialysis patients in the United States. Am J Med. 2003;115:291-297. doi:10.1016/ S0002-9343(03)00366-8

4. Davenport A. Audit of the effect of dialysate sodium concentration on inter-dialytic weight gains and blood pressure control in chronic haemodialysis patients. Nephron Clin Pract. 2006;104:c120-5. doi: 10.1159/000094544.

5. Davenport A, Cox C, Thuraisingham R. The importance of dialysate sodium concentration in determining interdialytic weight gains in chronic hemodialysis patients: the PanThames Renal Audit. Int J Artif Organs 2008;31:411417.

6. Krautzig S, Janssen U, Koch KM, Granolleras C, Shaldon S: Dietary salt restriction and reduction of dialysate sodium to control hypertension in maintenance hemodialysis patients. Nephrol Dial Transplant. 1998;13:552-3.

7. Kooman JP, van der Sande F, Leunissen K, Locatelli F. Sodium balance in hemodialysis therapy. Semin Dial. 2003;16:351-5. doi: 10.1046/j.1525-139X.2003.16070.x.

8. Sayarlioglu H, Erkoc R, Tuncer M, Soyoral Y, Esen R, Gumrukcuoglu HA, et al. Effects of low sodium dialysate in chronic hemodialysis patients: an echocardiographic study. Ren Fail. 2007;29:143-146. doi: 10.1080/08860220601095785.

9. Hecking M, Kainz A, Hörl WH, Herkner H, SunderPlassmann G. Sodium setpoint and sodium gradient: influence on plasma sodium change and weight gain. Am J Nephrol. 2011;33:39-48. doi: 10.1159/000322572.

10. Appel LJ, Brands MW, Daniels SR, Karanja N, Elmer PJ, Sacks FM. Dietary approaches to prevent and treat hypertension: a scientific statement from the American Heart Association. Hypertension. 2006;47:296-308. doi: 10.1161/01.HYP.0000202568.01167.B6.

11. Zoccali C, MMallamaci F. Hypertension. In: Daugirdas J, Blake P, Ing T, eds. Handbook of Dialysis. 5th ed. Philadelphia: Lippincott Williams \& Wilkins; 2014:579-84.

12. Flanigan MJ. Sodium flux and dialysate sodium in hemodialysis. Semin Dial. 1998;11:298-304.

13. Elshahawy Y, Sany D, Shawky S. Outcome of individualized dialysate sodium concentration for hemodialysis patients. Saudi J Kidney Dis Transpl. 2013;24:507-13. doi: 10.4103/1319-2442.111025.

14. Movilli E, Camerini C, Gaggia P, Zubani R, Feller P, Poiatti P, Pola A,et al. Role of dialysis sodium gradient on intradialytic hypertension: an observational study. Am J Nephrol. 2013;38:413-9. doi: 10.1159/000355974.

15. Weir MR: Hypervolemia and blood pressure: powerful indicators of increased mortality among hemodialysis patients. Hypertension. 2010;56:341-3. doi: 10.1161/ HYPERTENSIONAHA.110.156588.

Copyright $\odot 2016$ The Author(s); Published by Nickan Research Institute. This is an open-access article distributed under the terms of the Creative Commons Attribution License (http://creativecommons.org/licenses/by/4.0), which permits unrestricted use, distribution, and reproduction in any medium, provided the original work is properly cited. 